\title{
Mutagenesis and Identification of Sugarcane Mutants Using Survival on Polyethylene Glycol and Leaf Damage under Managed Water Stress
}

\author{
Napa Weksanthia $\left(\mathbb{D},{ }^{1}\right.$ Tanapon Chaisan $\mathbb{D}^{1,2}$, Wannasiri Wannarat $\mathbb{D}^{1},{ }^{1}$ \\ Songyos Chotchutima $\mathbb{}^{1},{ }^{1}$ and Peeranuch Jompuk ${ }^{3}$ \\ ${ }^{1}$ Department of Agronomy, Faculty of Agriculture, Kasetsart University, Bangkok 10900, Thailand \\ ${ }^{2}$ Center for Advanced Studies for Agriculture and Food, KU Institute for Advanced Studies, Kasetsart University, \\ Bangkok 10900, Thailand \\ ${ }^{3}$ Department of Applied Radiation and Isotope, Faculty of Science, Kasetsart University, Bangkok 10900, Thailand
}

Correspondence should be addressed to Tanapon Chaisan; fagrtpc@ku.ac.th

Received 26 July 2021; Revised 26 October 2021; Accepted 12 November 2021; Published 7 December 2021

Academic Editor: Magdi Abdelhamid

Copyright (c) 2021 Napa Weksanthia et al. This is an open access article distributed under the Creative Commons Attribution License, which permits unrestricted use, distribution, and reproduction in any medium, provided the original work is properly cited.

\begin{abstract}
Drought causes severe damage to sugarcane, reducing its product yield. Given Thailand's weather conditions and topography, a breeding program to develop new sugarcane genotypes with a high tolerance for water stress is important to the sugarcane industry. This study created new water stress tolerant sugarcane genotypes using ethyl methanesulfonate (EMS) mutagenesis in the sugarcane cultivar Khon Kaen 3. Using $16 \mathrm{mM}$ of EMS for $4 \mathrm{~h}$ induced callus mutagenesis (survival rate, 57.5\%). The survival rates of calli treated with $10 \mathrm{mM}$ of EMS for 2 and $4 \mathrm{~h}$ in selective media with $15 \%$ PEG were higher than that of non-EMS-treated calli. The selected calli survived and grew on selective media with $20 \%$ PEG, while non-EMS-treated calli did not grow. The mutant plantlets developed from EMS-treated calli on selective media with 20\% PEG for 4 weeks had varying survival rates: $72.25 \%$ (10 mM of EMS for $2 \mathrm{~h}$ ), $75.85 \%$ (10 mM of EMS for $4 \mathrm{~h})$, and $60.61 \%$ (16 mM of EMS for $4 \mathrm{~h})$. Both healthy mutant sugarcane plants $(2,086)$ and non-mutant plants $(234)$ were cultured on the media with $20 \%$ PEG for 16 weeks. Of these, 462 mutant sugarcane plantlets survived and developed on the media, but all the non-mutant sugarcane plantlets died during the selection process. Mutagenesis induced using treatment 4 produced the highest frequency of mutant sugarcane plantlets with water-stress tolerance (45.5\%). In total, 136 selected mutant sugarcane plants were transplanted to a greenhouse for evaluation under managed water stress. Fourteen mutant sugarcane plants stayed green after the third cycle of water stress, but the KK3 sugarcane cultivar showed damage on $50 \%$ of the leaves. Thus, EMS mutagenesis and evaluation using in vitro and greenhouse methods were successful in developing new sugarcane clones with high water-stress tolerance, which is important for sugarcane breeding programs.
\end{abstract}

\section{Introduction}

Sugarcane is an economic crop that has a substantial impact on the economy of Thailand, where it is the primary raw material for the production of sugar used in many highvalue products and downstream industries, including bioethanol and electricity production [1]. In 2020, Thailand ranked fourth in the world based on the volume of sugarcane produced (74.9 million tons). Drought is adversely affecting many of Thailand's economic crops, including sugarcane. Cane production in 2020 was dropped approximately $43 \%$, compared with the previous year, because of the drought [2]. Drought often occurs in the middle of Thailand's sugarcane planting season, often having a devastating effect on yield as it reduces the number of shoots per clump and stunts the sugarcane stalks. Sugarcane farmers cannot avoid this annual period of drought because sugarcane grows over a span of 12-15 months. Therefore, a systematic breeding program 
to develop new drought-tolerant sugarcane varieties is essential. Inducing mutation has been shown to be a viable method to create genetic variations, and it was possible to create new sugarcane genotypes for breeding programs.

It is well-known that physical and chemical mutagenesis are efficient methods for inducing genetic variation, with gamma rays, ethyl methanesulfonate (EMS), sodium azide, and 5-azacytidine frequently being used to trigger mutations, thereby creating new plant characteristics [3]. EMS is a chemical mutagen with high mutagenesis efficiency, and in vitro mutagenesis using EMS has been reported as an effective method for creating variations in crop plants [4]. Mutagenesis through EMS has been used to induce imazapyr tolerance, high aluminum resistance, and salt tolerance in sugarcane [5-8], and it has been used to successfully induce new crop genotypes that are more drought tolerance [9]. Given the high potential of EMS to induce mutagenesis, this should be a realistic method to develop new sugarcane clones that can better tolerate water deficits and drought field conditions.

Plant callus cells are an efficient plant material to be used for inducing mutagenesis because target mutant calli can be selected on selective media [10]. Furthermore, selected plant mutant calli can regenerate plants on culture media, and the genetics of cells in a mutant plant regenerated from callus are identical to the mother plant [11]. For sugarcane propagation, cell and tissue cultures are efficient methods for increasing the number of target clones. Calli are usually induced from young leaves and segments of young leaves generally after initiation using different concentrations of 2,4-dichlorophenoxyacetic acid (2,4-D) [12]. The maximum callus formation (80-85\%) was observed in MS media containing 3 and $4 \mathrm{mg} / \mathrm{l}$ of 2,4-D [13]. Callus induction medium was reported on Murashige and Skoog (MS) medium supplemented with 2,4-D, with the addition of water enhancing the growth of calli on this medium [14].

The regeneration of sugarcane calli can be controlled using 6-benzylamino purine (BAP), naphthaleneacetic acid (NAA), kinetin, and coconut water. In sugarcane, callus regeneration is highly efficient when plant growth regulators are combined and auxins and cytokinins are often used for supplementation in culture media for callus regeneration [15]. MS medium supplemented with NAA and BAP produced $98.9 \%$ regeneration in sugarcane variety CPF-246 [16], while kinetin and BAP could also regenerate plantlets in sugarcane [17].

Water-stress-tolerant plants can be examined and selected based on their capacity to survive on media supplemented with polyethylene glycol (PEG) to create conditions of water stress. PEG is a non-penetrating, inert, osmotic chemical that lowers the osmotic potential of nutrient solutions [18] and can be used to create water stress conditions on synthetic media. It can stimulate water stress in cultured plant cells without damaging the cells, and its high molecular weight reduces the potential of the water in the medium without the water being absorbed by the plant.

In vitro $\mathrm{PEG}$ selection for water-stress tolerance has been successful in many plants, such as rice [19] and sugarcane [20]. Selection for water-stress tolerance in sugarcane has been successful under managed water stress using physiological parameters and morphological parameters [21, 22]. Common morphological changes due to water stress that occur in sugarcane are leaf rolling, stomatal closure, inhibition of stalk and leaf growth, leaf senescence, and reduced leaf area [23]. However, morphological and physiological changes of sugarcane plants under water stress vary according to genotype, the level of stress, and the type of tissue $[24,25]$. A leaf damage score under water stress was used for the identification of water-stress tolerance in other crops [26].

Khon Kaen 3 (KK3) is the most popular, commonly planted sugarcane variety in Thailand because of its yield performance. However, KK3 is not tolerant to severe water deficit conditions. The presented study applied EMS mutagenesis for the KK3 cultivar to induce new mutant sugarcane genotypes for water-deficit tolerance. The mutant sugarcane genotypes were evaluated in vitro under water deficit conditions at the callus and plantlet stages. After regeneration, the selected mutant sugarcane plants were evaluated in the greenhouse under managed water stress to identify mutant sugarcane plants that thrived despite the stress.

\section{Materials and Methods}

2.1. Callus Initiation. Calli were induced from the commercial sugarcane cultivar KK3 Saccharum spp. hybrids. Sterile shoot tips of KK3 were cut into slices approximately 3-5 mm thick and placed on MS medium supplemented with three different treatments: $3 \mathrm{mg} / \mathrm{l}$ 2,4-D, $3 \mathrm{mg} / \mathrm{l} 2,4-$ $\mathrm{D}+0.5 \mathrm{mg} / \mathrm{l} \mathrm{BAP}$, or $3 \mathrm{mg} / \mathrm{l} 2,4-\mathrm{D}+10 \%$ coconut water. The sterilized explants were incubated in the dark at $25^{\circ} \mathrm{C} \pm 2{ }^{\circ} \mathrm{C}$.

2.2. Ethyl Methanesulfonate Mutagenesis. EMS mutagenesis was adapted from the methods described by Koch et al. [7]. Sugarcane calli were treated by EMS at 10 and $16 \mathrm{mM}$ for $2 \mathrm{~h}$ and EMS at $16 \mathrm{mM}$ for $4 \mathrm{~h}$. After EMS mutagenesis, $0.4 \mathrm{~g}$ of callus $(0.5 \mathrm{~mm}$ diameter) was cultured on callus culture medium and incubated in the dark at $25^{\circ} \mathrm{C} \pm 2{ }^{\circ} \mathrm{C}$ at a relative humidity of $40 \%$ for 2 weeks. Then, calli were subcultured every 2 weeks on the callus culture medium for 18 weeks and checked for calli that survived and grew. The survival rate and growth of EMS-treated calli were recorded.

\subsection{Selection of Mutant Calli and Plantlets under Selective} Media with PEG 15 or $20 \%$. The optimal PEG concentration for the creation of conditions of water stress in selective media was examined for EMS-treated calli and plantlets. Non-EMS-treated calli and regenerated plantlets of the KK3 sugarcane cultivar were cultured on MS media supplemented with different concentrations of PEG 6000: 0, 5, 10, $15,20,25$, and $30 \%$. In total, $0.2 \mathrm{~g}$ of calli was cultured on selective media for 4 weeks. The survival rate and growth of non-EMS-treated calli were recorded to identify the most efficient PEG concentration for the creation of conditions of water stress. 
Calli treated with EMS were cut into pieces $(1.5 \mathrm{~mm}$ diameter) and placed on semisolid MS media containing $15 \%$ and then $20 \%$ PEG, each time for 3 weeks. The calli that survived these water stress conditions were selected and transferred to a callus culture media. The selected calli were incubated in the dark at $25^{\circ} \mathrm{C} \pm 2^{\circ} \mathrm{C}$ for 3 weeks; then the calli were subcultured 2 times for 3 weeks each. The fresh weights of the selected calli were recorded.

After in vitro mutagenesis and the selection of waterstressed EMS-treated calli, the surviving calli were regenerated to mutant sugarcane plantlets for evaluation at the plantlet stage. The mutant calli were cultured on MS media, which were supplemented with $10 \%$ coconut water, $0.25 \mathrm{mg} / \mathrm{l}$ of $\mathrm{NAA}$, and $0.5 \mathrm{mg} / \mathrm{l}$ of kinetin for shoot regeneration (Supplementary Table 1). Calli were incubated under cool, white fluorescent light for $16 \mathrm{~h}$ a day at $25^{\circ} \mathrm{C} \pm 2{ }^{\circ} \mathrm{C}$ for 4 weeks. Plantlets regenerated from EMStreated calli were transferred to MS media without a plant growth regulator and incubated under cool, white fluorescent light for $16 \mathrm{~h}$ a day for 4 weeks.

Regenerated plantlets of the selected calli were cultured on MS media containing 20\% PEG, followed by incubation under cool white fluorescent light for $16 \mathrm{~h}$ daily at $25^{\circ} \mathrm{C} \pm 2^{\circ} \mathrm{C}$ for 16 weeks. The survival rate, number of shoots, number of roots, and root length were recorded.

\subsection{Evaluation of Mutant Sugarcane under Managed Water} Stress in Greenhouse. The mutant sugarcane plantlets were transplanted in a greenhouse for evaluation under managed water deficit conditions. The soil moisture was controlled using a wet sensor. After the plantlets had been transplanted for 1 month, the water stress conditions were managed by stopping the application of water that decreased the available soil moisture content to approximately $20 \%$ lower than field capacity. The mutant sugarcane plantlets were evaluated under these water stress conditions three times throughout the experimental period. Sugarcane plant leaf damage was scored using a modified method developed by Fen et al. [26]. The experiment was conducted using an augmented randomized complete block design (RCBD) for all three replications. The KK3 sugarcane cultivar was used as a control for the experiment. The mutant sugarcane clones for waterstress tolerance were identified by comparing their leaf damage scores with the leaf damage score of KK3.

2.5. Statistical Analysis. The collected data were statistically analyzed using analysis of variance for the experiments laid out in a completely randomized design and RCBD using the $\mathrm{R}$ program software [27]. Means between treatment were compared based on the least significant difference at $P \leq 0.05$ (significant) and $P \leq 0.01$ (highly significant).

\section{Results}

3.1. Callus Induction. Callus formation was discovered on leaf tissue after 7 days of culture on the callus induction media. The MS media supplemented with $3 \mathrm{mg} / \mathrm{l}$ of $2,4-\mathrm{D}$ produced the highest rate of callus initiation (96.43\%); the second-highest rate was observed in MS media supplemented with $3 \mathrm{mg} / \mathrm{l}$ of $2,4-\mathrm{D}$ plus $15 \%$ coconut water (74.07\%), as shown in Table 1. The lowest rate of callus induction was produced using the MS media supplemented with $3 \mathrm{mg} / \mathrm{l}$ of 2,4-D, and $0.5 \mathrm{mg} / \mathrm{l}$ of BAP $(9.47 \%)$.

The calli on the MS media containing $3 \mathrm{mg} / \mathrm{L}$ of $2,4-\mathrm{D}$ were yellowish and watery, while the calli on the MS media supplemented with $3 \mathrm{mg} / \mathrm{L}$ of $2,4-\mathrm{D}$ and $0.5 \mathrm{mg} / \mathrm{L}$ of BAP were brown and watery. Calli induced on MS media supplemented with $3 \mathrm{mg} / \mathrm{L}$ of $2,4-\mathrm{D}$ plus $15 \%$ of coconut water were mixed, being somewhat yellow and white in color (Supplementary Figure 1). Both friable and compact calli were found on the culture media. The biggest callus was on the MS media containing $3 \mathrm{mg} / \mathrm{L}$ of $2,4-\mathrm{D}$ plus $15 \%$ coconut water, with the average size of the callus in this treatment being $0.8 \mathrm{~cm}$ in diameter.

3.2. EMS Mutagenesis. The survival rates of calli from the EMS mutagenesis treatments and the control were significantly different and varied from 57.5 to $100 \%$ (Table 2 ). The highest survival rates at $100 \%$ were for the calli from EMSinduced mutagenesis with $10 \mathrm{mM}$ EMS for $2 \mathrm{~h}$. Friable callus formation was different in each EMS mutagenesis treatment. The lowest average survival rate was in the treatment of $16 \mathrm{mM}$ of EMS for $4 \mathrm{~h}$. The treatment of $16 \mathrm{mM}$ of EMS for $4 \mathrm{~h}$ produced less than $20 \%$ friable callus formation (Table 2 ).

\subsection{In Vitro Evaluation of EMS-Treated Calli under Water} Stress Conditions. Non-EMS-treated sugarcane calli were cultured on MS media containing PEG 6000 concentrations of $0,5,10,15,20,25$, and $30 \%$ for 3 weeks. The results showed that the growth of calli decreased when the PEG concentration increased (Supplementary Figure 2). Concentrations of PEG significantly affected the callus fresh weight compared to the initial callus fresh weight of $0.6 \mathrm{~g}$. The highest callus fresh weight was $1.13 \mathrm{~g}$ (188.33\% of the initial weight) for callus cultured on the medium without PEG. The calli cultured on MS medium with PEG concentrations of 5 and $10 \%$ had slow growth, with fresh weights after culture under the water stress conditions being 0.94 and $0.76 \mathrm{~g}$, respectively. The growth of calli was inhibited on MS medium with 15\% PEG, and the callus fresh weight after the treatment did not differ from the initial weight of $0.6 \mathrm{~g}$. The calli cultured on MS medium with $20 \%$ PEG concentration decreased the fresh weight from 0.6 to $0.56 \mathrm{~g}$, with a decline in fresh weight of $6.67 \%$. The callus fresh weights of MS medium supplemented with 25 and $30 \%$ of PEG were 0.52 and $0.41 \mathrm{~g}$, respectively, with decreasing rates of 13.33 and $31.67 \%$, respectively. According to this finding, the MS media containing 15 and 20\% of PEG were used for screening mutant calli for water-deficit tolerance.

Evaluation of EMS-treated calli on the MS media containing $15 \%$ of PEG for 4 weeks showed a progressively decreasing weight (Table 3). The weights of the EMS-treated calli in the three treatments and the control on MS media containing $15 \%$ of PEG were significantly different. Evaluation of calli on the MS media containing 15\% PEG for 6 weeks revealed that the weight of the EMS-treated calli was 
TABLE 1: Effect of culture medium on callus induction, characterization, and growth after culture for 4 weeks.

\begin{tabular}{|c|c|c|c|c|c|c|}
\hline \multicolumn{3}{|c|}{ MS basal medium supplemented with } & \multirow{2}{*}{ Callus formation (\%) } & \multicolumn{2}{|c|}{ Callus characterization } & \multirow{2}{*}{ Diameter of callus $(\mathrm{cm})$} \\
\hline 2,4-D (mg/l) & $\mathrm{BAP}(\mathrm{mg} / \mathrm{l})$ & Coconut water $(\%)$ & & Color & Texture & \\
\hline 3.00 & 0.50 & 0.00 & $9.47^{\mathrm{c}}$ & Brown & Watery & $0.33^{\mathrm{b}}$ \\
\hline 3.00 & 0.00 & 15.00 & $74.07^{\mathrm{b}}$ & Yellow or white & Friable and compact & $0.80^{\mathrm{a}}$ \\
\hline 3.00 & 0.00 & 0.00 & $96.43^{\mathrm{a}}$ & Yellowish & Compact & $0.30^{\mathrm{b}}$ \\
\hline
\end{tabular}

Means with different letters within a column indicate significant differences $(P<0.05)$ according to the least significant difference test (LSD).

TABLE 2: Influence of ethyl methanesulfonate (EMS) mutagenesis conditions on survival rate and friable callus development.

\begin{tabular}{lcccc}
\hline Treatment $(T)$ & EMS concentrations $(\mathrm{mM})$ & Duration of EMS treatment $(\mathrm{h})$ & Friable callus development & Survival rate of callus (\%) \\
\hline$T 1$ & 0 & 0 & $>75 \%$ & $100.00^{\mathrm{a}}$ \\
$T 2$ & 10 & 2 & $51-75 \%$ & $100.00^{\mathrm{a}}$ \\
$T 3$ & 10 & 4 & $25-50 \%$ & $77.50^{\mathrm{ab}}$ \\
$T 4$ & 16 & 4 & $<25 \%$ & $57.50^{\mathrm{b}}$ \\
\hline
\end{tabular}

Means with different letters within a column indicate significant differences $(P<0.05)$ according to LSD. T1: non-EMS-treated calli, T2: calli treated with $10 \mathrm{mM}$ EMS for $2 \mathrm{~h}, \mathrm{T3}$ : calli treated with $10 \mathrm{mM}$ EMS for $4 \mathrm{~h}$, and T4: calli treated with $16 \mathrm{mM}$ EMS for $4 \mathrm{~h}$.

TABLE 3: Growth and development evaluation of ethyl methanesulfonate (EMS) treated calli on selective medium supplemented with $15 \%$ or $20 \%$ PEG for 4 weeks.

\begin{tabular}{|c|c|c|c|c|c|c|c|}
\hline \multirow{2}{*}{$\begin{array}{l}\text { EMS concentration } \\
(\mathrm{mM}) \\
\text { Duration for EMS } \\
\text { treatment }(\mathrm{h})\end{array}$} & \multicolumn{4}{|c|}{ Selective medium supplemented with $15 \%$ PEG } & \multicolumn{3}{|c|}{ Selective medium supplemented with $20 \%$ PEG } \\
\hline & & $\begin{array}{l}\text { Initial weight } \\
\text { (g) }\end{array}$ & $\begin{array}{c}\text { Weight of callus after } \\
\text { evaluation }(\mathrm{g})\end{array}$ & $\begin{array}{c}\text { Weight loss } \\
(\%)\end{array}$ & $\begin{array}{l}\text { Initial weight } \\
(\mathrm{g})\end{array}$ & $\begin{array}{c}\text { Weight of callus } \\
\text { after } \\
\text { evaluation (g) }\end{array}$ & $\begin{array}{l}\text { Weight loss } \\
\text { (\%) }\end{array}$ \\
\hline 0 & 0 & 2.00 & $0.27^{\mathrm{c}}$ & $86.50 \%^{\mathrm{a}}$ & 2.00 & $0.08^{\mathrm{b}}$ & $96.0 \%^{\mathrm{a}}$ \\
\hline 10 & 2 & 2.00 & $1.13^{\mathrm{a}}$ & $43.50 \%^{\mathrm{c}}$ & 2.00 & $0.52^{\mathrm{a}}$ & $74.0 \%^{\mathrm{b}}$ \\
\hline 10 & 4 & 2.00 & $0.87^{\mathrm{ab}}$ & $56.50 \%^{\mathrm{c}}$ & 2.00 & $0.26^{\mathrm{a}}$ & $87.0 \%^{\mathrm{b}}$ \\
\hline 16 & 4 & 2.00 & $0.58^{\mathrm{bc}}$ & $71.00 \%^{\mathrm{b}}$ & 2.00 & $0.33^{\mathrm{a}}$ & $83.5 \%^{\mathrm{b}}$ \\
\hline$F$-test & & & $* *$ & $* *$ & & $* *$ & $* *$ \\
\hline
\end{tabular}

Means with different letters within a column indicate significant differences according to LSD. ${ }^{* * * *}$ significant at $P<0.05,0.01$, respectively.

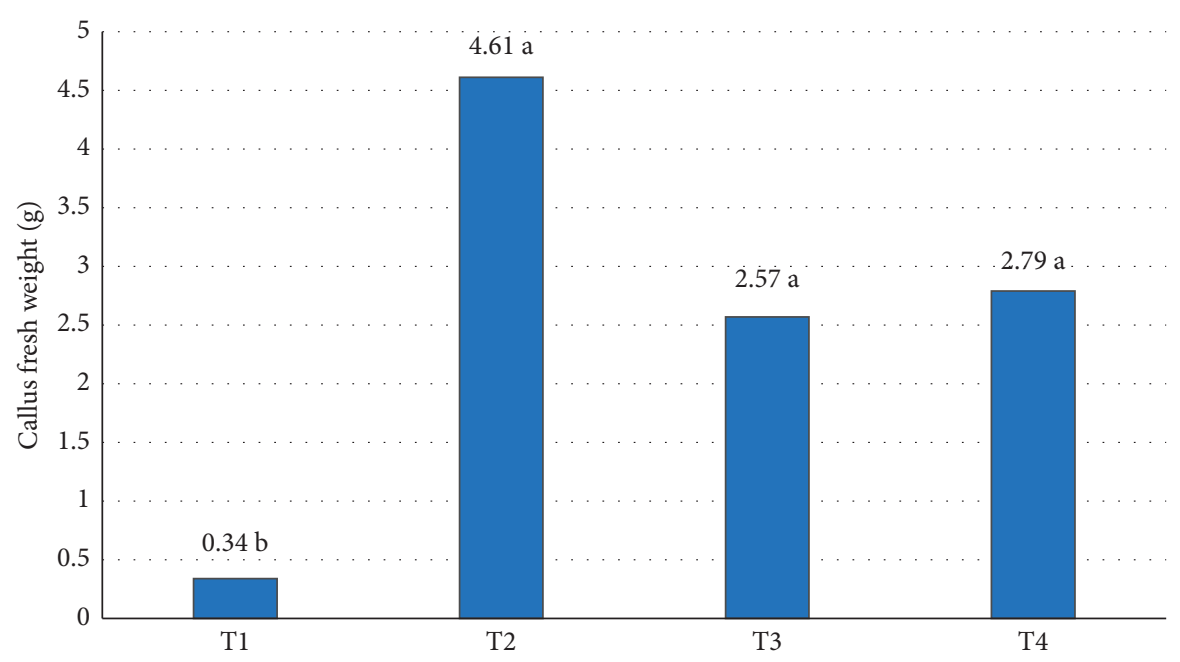

FIGURE 1: Weight of EMS-treated calli after culture on MS medium + 15\% PEG for 6 weeks. T1: non-EMS-treated calli; T2: calli treated with $10 \mathrm{mM}$ EMS for $2 \mathrm{~h}$; T3: calli treated with $10 \mathrm{mM}$ EMS for $4 \mathrm{~h}$; and T4: calli treated with $16 \mathrm{mM}$ EMS for $4 \mathrm{~h}$. 


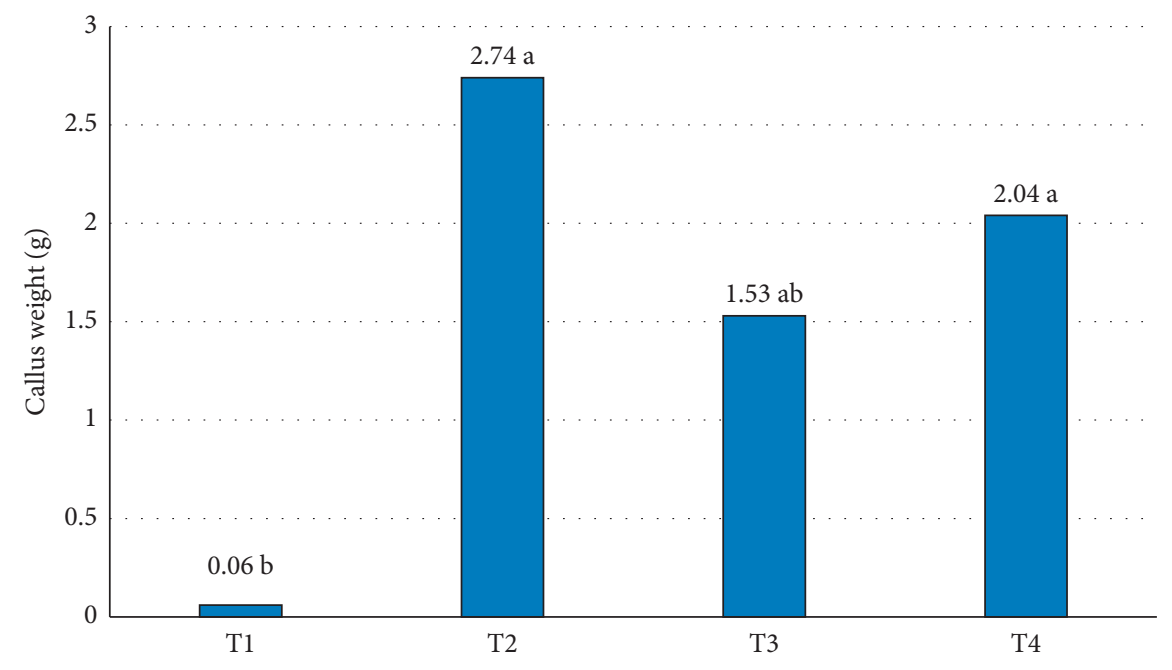

FIGURE 2: Weight of EMS-treated calli after culture on MS medium + 20\% PEG for 6 weeks. T1: non-EMS-treated calli; T2: calli treated with $10 \mathrm{mM}$ EMS for $2 \mathrm{~h}$; T3: calli treated with $10 \mathrm{mM}$ EMS for $4 \mathrm{~h}$; and T4: calli treated with $16 \mathrm{mM}$ EMS for $4 \mathrm{~h}$.

TABLE 4: Regeneration rate and development of mutant sugarcane plantlets on regeneration media and survival rate of mutant sugarcane plantlets on selective medium with $20 \%$ PEG.

\begin{tabular}{lcccccccc}
\hline $\begin{array}{l}\text { EMS } \\
\text { concentration } \\
(\mathrm{mM})\end{array}$ & $\begin{array}{c}\text { Duration of } \\
\text { EMS } \\
\text { treatment }(\mathrm{h})\end{array}$ & $\begin{array}{c}\text { No. of } \\
\text { shoots/ } \\
\text { callus }\end{array}$ & $\begin{array}{c}\text { Shoot } \\
\text { regeneration } \\
\text { rate }(\%)\end{array}$ & $\begin{array}{c}\text { Average } \\
\text { number of } \\
\text { plantlets }\end{array}$ & $\begin{array}{c}\text { Average } \\
\text { plantlet } \\
\text { height }(\mathrm{cm})\end{array}$ & $\begin{array}{c}\text { Average } \\
\text { number of } \\
\text { roots }(\mathrm{cm})\end{array}$ & $\begin{array}{c}\text { Root } \\
\text { length } \\
(\mathrm{cm})\end{array}$ & $\begin{array}{c}\text { Plantlet survival } \\
\text { rate on MS + 20\% } \\
\text { PEG }(\%)\end{array}$ \\
\hline 0 & 0 & 2.64 & 70.63 & $18.00^{\mathrm{b}}$ & 5.47 & $0.88^{\mathrm{b}}$ & 1.24 & $39.78^{\mathrm{b}}$ \\
10 & 2 & 2.76 & 88.75 & $25.99^{\mathrm{b}}$ & 5.46 & $1.55^{\mathrm{b}}$ & 1.57 & $72.25^{\mathrm{a}}$ \\
10 & 4 & 1.93 & 85.63 & $38.33^{\mathrm{ab}}$ & 5.39 & $1.37^{\mathrm{b}}$ & 1.45 & $75.85^{\mathrm{a}}$ \\
16 & 4 & 2.98 & 95.63 & $50.13^{\mathrm{a}}$ & 5.24 & $3.60^{\mathrm{a}}$ & 1.23 & $60.61^{\mathrm{a}}$ \\
F-test & & NS & NS & $*^{* *}$ & NS & $*^{*}$ & NS \\
\hline
\end{tabular}

Means with different letters within a column indicate significant differences according to LSD. ${ }^{\text {NS,*,**}}$ non-significant or significant at $P<0.05,0.01$, respectively.

higher than for non-EMS-treated calli. The weight of the EMS-treated calli ranged from 4.61 to $2.57 \mathrm{~g}$, while the nonEMS-treated callus had the lowest callus weight $(0.34 \mathrm{~g})$, as shown in Figure 1.

Selected EMS-treated calli from the MS media containing $15 \%$ of PEG were cultured on MS media containing $20 \%$ PEG for 4 weeks. The weight of EMS-treated calli after culture on the media differed significantly. The weight of EMS-treated calli for each treatment on the MS media with $20 \%$ PEG was lower than those on the selective medium with 15\% PEG. The selected EMS-treated calli from a selective medium with 15\% PEG could survive on selective media with $20 \%$ PEG, while the control could not survive on the selective media after only 1 month of culture on the media. The weight of EMS-treated calli ranged from 2.47 to $1.53 \mathrm{~g}$ (Figure 2).

3.4. Mutant Plantlet Regeneration and Evaluation under Water Stress Conditions. The number of mutant calli regenerated to plantlets did not differ significantly in the four treatments (Table 4). However, significant differences were found in the average number of regenerated plantlets among the four EMS treatments. Mutant calli treated with $16 \mathrm{mM}$ of EMS for $4 \mathrm{~h}$ produced the highest mean number of regenerated plantlets (50.13), while non-EMS-treated calli produced the lowest (18.00).

Mutant sugarcane plantlets regenerated from the EMStreated calli and plantlets of KK3 cultivar were evaluated on MS media with 20\% PEG for 4 weeks. The average numbers of roots were significantly different (Table 4). Furthermore, the survival rates of the mutant sugarcane varied noticeably: mutant plantlets from $10 \mathrm{mM}$ of EMS for $2 \mathrm{~h}(72.25 \%)$, $10 \mathrm{mM}$ of EMS for $4 \mathrm{~h}(75.85 \%)$, and $16 \mathrm{mM}$ of EMS for $4 \mathrm{~h}$ (60.61\%; Table 4). The lowest survival rate of sugarcane plants on selective media was recorded for non-mutant sugarcane plants (39.78\%). All the mutant plantlets on the selection media with 20\% PEG for 16 weeks survived; however, all the non-mutant sugarcane plantlets died.

In total, 136 sugarcane mutant genotypes were transplanted for evaluation under managed water stress conditions in a greenhouse. Damaged leaf areas were not visible after the first cycle of water stress. However, by the third cycle of water stress, damaged leaf areas were easily visible to the naked eye. Leaf damage scores after the third cycle of water stress were ranked from 0 to 10; the leaf damage score for KK3 (non-mutant) was 5.9. Leaf damage among the samples differed significantly. Out of the 136 sugarcane mutant genotypes, 14 mutant plants were evaluated with leaf damage scores lower than those of KK3. These 14 mutant 


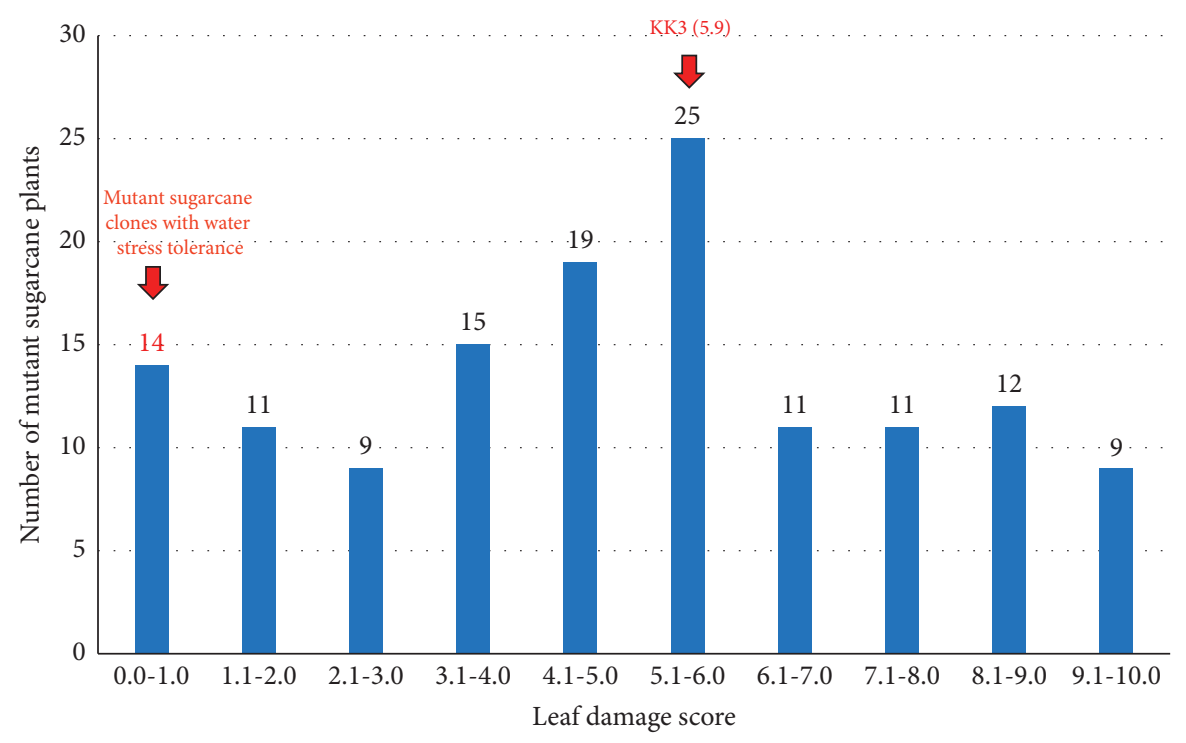

FigURE 3: Leaf damage scores of mutant sugarcane clones after evaluation for water-stress tolerance in a greenhouse.

sugarcane plants had leaf damage scores ranging from 0 to 0.8 (Figure 3).

\section{Discussion}

Compact and friable calli were discovered in equal proportions on the MS media containing $3 \mathrm{mg} / \mathrm{L}$ of $2,4-\mathrm{D}+10 \%$ $(v / v)$ coconut water, which was consistent with the findings of Patel [28]. Most of the calli induced on MS media containing $3 \mathrm{mg} / \mathrm{L}$ of $2,4-\mathrm{D}$ were compact calli, which are difficult to regenerate in plantlets [29]. The MS medium supplemented with 2,4-D plus coconut water has been used effectively in other research studies to induce friable calli in sugarcane [30-32]. Thus, MS medium containing $3 \mathrm{mg} / \mathrm{L}$ of $2,4-\mathrm{D}+10 \%$ coconut water $(v / v)$ was recommended for callus induction media to prepare calli for EMS mutagenesis.

Concentrations of EMS at 10.00-32.25 mM were used successfully to induce mutations in sugarcane [33]. However, the best conditions for EMS mutagenesis of the sugarcane cultivar KK3 were required to initiate genetic variation. Calli treated with $16 \mathrm{mM}$ of EMS for $4 \mathrm{~h}$ resulted in the death of nearly $50 \%$ of the plants. The most suitable conditions for EMS mutagenesis of the KK3 sugarcane calli were $16 \mathrm{mM}$ of EMS for $4 \mathrm{~h}$, which was in agreement with Koch et al. [7].

Water stress on selective media using PEG is an efficient method for screening calli for water-stress tolerance [34, 35]. If mutant calli can adjust their cell water potential under conditions of water deficit, then the mutant calli will be able to survive on the selective medium containing PEG [36]. Concentrations of PEG at 5 and $10 \%$ slowed the growth of calli, while PEG concentrations of 15 or $20 \%$ inhibited the growth of calli and the cells died within 8 weeks of culture. PEG concentrations of 25 and 30\% decreased the weight of calli after the first week of culture, with most calli cultured on the media not surviving after culture for 4 weeks. PEG concentrations at 25 or $30 \%$ were too high to evaluate for water-stress tolerance. Therefore, PEG concentrations of 15 or $20 \%$ were used as selective media for evaluating the waterstress tolerance of EMS-treated calli.

In the present study, some of the mutant calli could develop on the selective medium supplemented with 15 or $20 \%$ of PEG, respectively. Non-EMS-treated calli could not survive on the same selective medium supplemented with 15 or $20 \%$ of PEG. The study determined that the selected EMStreated calli were tolerant to water stress.

The water stress-tolerant calli were regenerated to plantlets, and the plantlets were evaluated under conditions of water deficit using MS media supplemented with 20\% PEG to confirm their tolerance. Mutant sugarcane plantlets regenerated from selected mutant calli survived on selective media containing 20\% PEG, while non-mutant plantlets of sugarcane cultivar KK3 died under conditions of water deficit after culture on selective media. During this process of assessing the water-stress tolerance of plantlets, a group of mutant plantlets was identified that could survive on the selective media after culture for 16 weeks, while the non-mutant plantlets all died after culture on the selective media for 16 weeks. These results confirmed that the selected mutant plantlets on selective media were tolerant to water stress. Furthermore, the results indicated that in vitro evaluation of water-stress tolerance on MS media supplemented with $20 \%$ PEG was a highly effective screening method.

The mutant sugarcane clones presented damaged leaf areas in the third cycle of drought stress and scoring the water-stress tolerance of each clone could carry out using visual inspection, while the second cycle of drought produced small dry areas on the sugarcane leaves. This could have been due to the root $\mathrm{H}_{2} \mathrm{O}_{2}$ concentration in the third cycle of water stress being higher than in the first and second cycles; consequently, the accumulation of $\mathrm{H}_{2} \mathrm{O}_{2}$ in roots in the third cycle resulted in root damage [22]. Reduced leaf area is a common response of plants when plant roots are damaged under water stress conditions [37]. The damaged leaf areas in the third cycle were categorized based on the level of water-stress tolerance of each clone, allowing 
leaf damage scoring to be applied as an efficient and economical method for the selection of tolerance to water stress in sugarcane clones under managed water stress conditions [38].

The water stress evaluation in the greenhouse confirmed that the in vitro-selected mutant sugarcane clones of the present study were tolerant to serious water stress conditions based on their damaged leaf area. Fourteen mutant sugarcane plants stayed green under serious water stress, but the KK3 cultivar presented approximately 50\% leaf damage. Under conditions of water stress on selective media with PEG, the mutant sugarcane plantlets selected for their waterstress tolerance may have had mechanisms to adjust the cell water potential or to protect against cell damage, while the susceptible clones were unable to adapt to water stress and eventually died [39-41]. The findings in this study were consistent with other studies that mutant plants presented mechanisms to overcome conditions of dehydration [42, 43]. However, only 14 sugarcane mutant plants presented leaf damage scores lower than those of KK3 under serious water stress in a greenhouse. The mutant sugarcane plants evaluated under water stress for 3 cycles displayed high levels of root damage because of the high accumulation of $\mathrm{H}_{2} \mathrm{O}_{2}$ in roots, and only sugarcane mutants with defense mechanisms against oxidative damage in root tissue could survive the stress conditions [22, 38]. The results of the present study indicated that the 14 mutant sugarcane plants contained mechanisms to overcome conditions of dehydration and had defense mechanisms against oxidative damage in roots. These 14 mutant sugarcane plants will be utilized as sources of sugarcane germplasm for breeding sugarcane with water-stress tolerance in Thailand.

\section{Conclusions}

EMS mutagenesis was applied to induce mutation in the KK3 sugarcane cultivar. Using 3 steps of water stress evaluation (at the calli, plantlet, and seedling stages), 14 out of 136 selected mutant sugarcane plants were confidently identified as new sugarcane clones with water-stress tolerance. The 14 sugarcane mutants survived on selective media supplemented with $15 \%$ or $20 \%$ PEG and stayed green even after the third cycle of water stress conditions in a greenhouse; in contrast, the popular Thai KK3 sugarcane cultivar presented 50\% damaged leaf areas. During the greenhouse evaluation of the mutant sugarcane plants based on their water-stress tolerance, tolerance was categorized by scoring the damaged leaf area on each plant after the third cycle of water stress.

\section{Data Availability}

The data used to support the findings of this study are available from the corresponding author upon request.

\section{Conflicts of Interest}

The authors declare that there are no conflicts of interest regarding the publication of this paper.

\section{Acknowledgments}

The Faculty of Agriculture, Kasetsart University, Bangkok, Thailand, and the Kasetsart Agricultural and Agro-Industrial Product Improvement Institute provided resources to carry out this study at Kasetsart University. This work was supported by the Thailand Research Fund (grant no. 2557NRCT53970) and the Center for Advanced Studies for Agriculture and Food, Institute for Advanced Studies, Kasetsart University, Bangkok, Thailand, under the Higher Education Research Promotion and National Research University Project of Thailand, Office of the Higher Education Commission, Ministry of Education, Thailand.

\section{Supplementary Materials}

Supplementary Table 1: regeneration media of sugarcane calli for determining shoot regeneration, number of plantlets, and plantlet development. Supplementary Figure 1: effect of callus induction media on callus induction and characteristics. Supplementary Figure 2: evaluation of different polyethylene glycol (PEG) concentrations for growth and development of ethyl-methanesulfonate-treated calli. (Supplementary Materials)

\section{References}

[1] P. Sukyai, N. Yingkamhaeng, N. T. Lam et al., "Research and development prospects for sugarcane and sugar industry in Thailand," Sugar Tech, vol. 18, pp. 583-587, 2016.

[2] N. Khumla, S. Sakuanrungsirikul, P. Punpee et al., "Sugarcane breeding, germplasm development and supporting genetics research in Thailand," Sugar Tech, vol. 18, pp. 583-587, 2021.

[3] A. M. Van Harten, "Mutation breeding of vegetatively propagated ornamentals," in Breeding for Ornamentals: Classical and Molecular Approaches, A. Vainstein, Ed., pp. 105-127, Springer, Berlin, Germany, 2002.

[4] N. E. Hofmann, R. Raja, R. L. Nelson, and S. S. Korban, "Mutagenesis of embryogenic cultures of soybean and detecting polymorphisms using RAPD markers," Biologia Plantarum, vol. 48, no. 2, pp. 173-177, 2004.

[5] S. S. Gadakh, D. U. Patel, and A. B. Patil, "Evaluation of sugarcane (Saccharum spp. complex) mutants for yield, yield contributing traits and quality parameters," International Journal of Advanced Biological Research, vol. 5, pp. 220-228, 2015.

[6] M. Kenganal, R. R. Hanchinal, and H. L. Nadaf, "Ethyl methane sulphonate (EMS) induced mutation and selection for salt tolerance in sugarcane in vitro," Indian Journal of Plant Physiology, vol. 13, pp. 405-410, 2008.

[7] A. C. Koch, S. Ramgareeb, R. S. Rutherford, S. J. Snyman, and M. P. Watt, "An in vitro mutagenesis protocol for the production of sugarcane tolerant to the herbicide imazapyr," In Vitro Cellular and Developmental Biology-Plant, vol. 48, no. 4, pp. 417-427, 2012.

[8] R. Purnamaningsih and S. Hutami, "Increasing Al-tolerance of sugarcane using ethyl methane sulphonate and in vitro selection in the low pH media," Journal of Biosciences, vol. 23, pp. 1-6, 2016.

[9] X. Serrat, R. Esteban, N. Guibourt, L. Moysset, S. Nogués, and E. Lalanne, "EMS mutagenesis in mature seed-derived rice 
calli as a new method for rapidly obtaining TILLING mutant populations," Plant Methods, vol. 10, no. 1, 2014.

[10] R. Wekesa, J. M. Onguso, B. A. Nyende, and L. S. Wamocho, "Sugarcane in vitro culture technology: opportunities for Kenyaâpos sugar industry," African Journal of Biotechnology, vol. 14, pp. 3170-3178, 2015.

[11] A. Ali, S. Naz, S. S. Alam, and J. Iqbal, "In vitro induced mutation for screening of red rot (Colletotrichum falcatum) resistance in sugarcane (Saccharum offinarum)," Pakistan Journal of Botany, vol. 39, pp. 1979-1994, 2007.

[12] Z. G. Jahangir, I. A. Nasir, R. A. Sial, M. A. Javid, and T. Husnain, "Various hormonal supplementations activate sugarcane regeneration in-vitro," Journal of Agricultural Science, vol. 2, pp. 231-237, 2010.

[13] V. S. Patal, R. Metha, D. Singh, D. U. Patel, and S. C. Mali, "Callus induction \& whole plant regeneration in sugarcane (Saccharum spp. complex) variety CO 86032," Green Farming, vol. 6, pp. 1-5, 2015.

[14] Arjun and R. Srinath, "Callus induction and organogenesis in sugarcane (Saccharum officinarum L.) var 93v297," International Letters of Natural Sciences, vol. 48, pp. 14-22, 2015.

[15] E. F. George, M. A. Hall, and G. J. De Klerk, "Plant propagation by tissue culture," Background, vol. 1, pp. 205-226, 2008.

[16] S. Jamil, R. Shahzad, G. M. Talha et al., "Optimization of protocols for in vitro regeneration of sugarcane (Saccharum officinarum)," International Journal of Agronomy, vol. 2017, Article ID 2089381, 8 pages, 2017.

[17] M. Tesfa and M. Ftwi, "In vitro plant regeneration of sugarcane (Saccharum spp.) variety inoculated under different levels of plant growth regulators," Journal of Plant Biochemistry and Physiology, vol. 6, pp. 1-4, 2018.

[18] T. Errabii, C. B. Gandonou, H. Essalmani, J. Abrini, M. Idaomar, and N. S. Senhaji, "Growth, proline and ion accumulation in sugarcane callus cultures under droughtinduced osmotic stress and its subsequent relief," African Journal of Biotechnology, vol. 5, pp. 1488-1493, 2008.

[19] R. Joshi, A. Shukla, and R. K. Sairam, "In vitro screening of rice genotypes for drought tolerance using polyethylene glycol," Acta Physiologiae Plantarum, vol. 33, no. 6, pp. 2209-2217, 2011.

[20] N. Munir and F. Aftab, "The role of polyethylene glycol (PEG) pretreatment in improving sugarcane's salt $(\mathrm{NaCl})$ tolerance," Turkish Journal of Botany, vol. 33, pp. 407-415, 2009.

[21] S. W. V. Basnayake, R. Moyle, and R. G. Birch, "Embryogenic callus proliferation and regeneration conditions for genetic transformation of diverse sugarcane cultivars," Plant Cell Reports, vol. 30, no. 3, pp. 439-448, 2011.

[22] F. C. C. Marcos, N. M. Silveira, P. E. R. Marchiori et al., "Drought tolerance of sugarcane propagules is improved when origin material faces water deficit," PLoS One, vol. 13, no. 12, Article ID e0206716, 2018.

[23] N. G. Inman-Bamber, P. Lakshmanan, and S. Park, "Sugarcane for water-limited environments: theoretical assessment of suitable traits," Field Crops Research, vol. 134, pp. 95-104, 2012.

[24] D. Bartels and R. Sunkar, "Drought and salt tolerance in plants," Critical Reviews in Plant Sciences, vol. 24, no. 1, pp. 23-58, 2005.

[25] J. P. d. Graça, F. A. Rodrigues, J. R. B. Farias, M. C. N. d. Oliveira, C. B. Hoffmann-Campo, and S. M. Zingaretti, "Physiological parameters in sugarcane cultivars submitted to water deficit," Brazilian Journal of Plant Physiology, vol. 22, no. 3, pp. 189-197, 2010.
[26] L. L. Fen, M. R. Ismail, B. Zulkarami, M. S. A. Rahman, and M. R. Islam, "Physiological and molecular characterization of drought responses and screening of drought tolerant rice varieties," Bioscience Journal, vol. 31, no. 3, pp. 709-718, 2015.

[27] R Core Team, R: A Language and Environment for Statistical Computing, R Foundation for Statistical Computing, Vienna, Austria, 2017.

[28] R. S. Patel, Induction of variability through callus culture in sugarcane (Saccharum officinarum L.) variety CoN 95132, Ph.D. Thesis, Navsari Agricultural University, Gujarat, India, 2007.

[29] C. Van der Vyver, T. Conradie, J. Kossmann, and J. Lloyd, "In vitro selection of transgenic sugarcane callus utilizing a plant gene encoding a mutant form of acetolactate synthase," In vitro Cellular and Developmental Biology-Plant, vol. 49, pp. 198-206, 2013.

[30] R. Dibax, G. B. d. Alcantara, M. P. Machado, J. C. B. Filho, and R. A. d. Oliveira, "Protocol optimization and histological analysis of in vitro plant regeneration of RB92579 and RB93509 sugarcane cultivars," Ciência Rural, vol. 43, no. 1, pp. 49-54, 2012.

[31] G. Franklin, S. Arvinth, C. J. Sheeba, M. Kanchana, and N. Subramonian, "Auxin pretreatment promotes regeneration of sugarcane (Saccharum spp. hybrids) midrib segment explants," Plant Growth Regulation, vol. 50, no. 2-3, pp. 111-119, 2006.

[32] R. Khamrit, P. Jaisil, and S. Bunnag, "Callus induction, regeneration and transformation of sugarcane (Saccharum officinarum L.) with chitinase gene using particle bombardment," African Journal of Biotechnology, vol. 24, pp. 66126618, 2012.

[33] S. Sadat and S. M. Hoveize, "Mutation induction using ethyl methanesulfonate (EMS) in regenerated plantlets of two varieties of sugarcane CP48-103 and CP57-614," African Journal of Agricultural Research, vol. 7, pp. 1282-1288, 2012.

[34] J. Biswas, B. Chowdhury, A. Bhattacharya, and A. B. Mandal, "In vitro screening for increased drought tolerance in rice," In Vitro Cellular and Developmental Biology-Plant, vol. 38, no. 5, pp. 525-530, 2002.

[35] H. K. Moon, S. Park, Y. W. Kim, and S.-H. Kim, "Somatic embryogenesis and plantlet production using rejuvenated tissues from serial grafting of a mature Kalopanax septemlobus tree," In Vitro Cellular \& Developmental Biology-Plant, vol. 44, pp. 119-127, 2008.

[36] S. Rao and J. Ftz., "In vitro selection and characterization of polyethylene glycol (PEG) tolerant callus lines and regeneration of plantlets from the selected callus lines in sugarcane (Saccharum officinarum L.)," Physiology and Molecular Biology of Plants, vol. 19, no. 2, pp. 261-268, 2013.

[37] Arjun and S. Rao, "Callus induction and organogenesis in sugarcane (Saccharum officinarum L.) var 93v297," International Letters of Natural Sciences, vol. 48, pp. 14-22, 2015.

[38] T. H. S. Ferreira, M. S. Tsunada, D. Bassi et al., "Sugarcane water stress tolerance mechanisms and its implications on developing biotechnology solutions," Frontiers of Plant Science, vol. 8, 2017.

[39] P. E. Abbate, J. L. Dardanelli, M. G. Cantarero, M. Maturano, R. J. M. Suero, and E. E. Sueroa, "Climatic and water availability effects on water-use efficiency in wheat," Crop Science, vol. 44, no. 2, pp. 474-483, 2004.

[40] M. Farooq, A. Wahid, N. Kobayashi, D. Fujita, and S. M. A. Basra, "Plant drought stress: effects, mechanisms and management," Agronomy for Sustainable Development, vol. 29, no. 1, pp. 185-212, 2009. 
[41] B. Jongdee, S. Fukai, and M. Cooper, "Leaf water potential and osmotic adjustment as physiological traits to improve drought tolerance in rice," Field Crops Research, vol. 76, no. 2-3, pp. 153-163, 2002.

[42] A. G. Bengough, B. M. McKenzie, P. D. Hallett, and T. A. Valentine, "Root elongation, water stress, and mechanical impedance: a review of limiting stresses and beneficial root tip traits," Journal of Experimental Botany, vol. 62, no. 1, pp. 59-68, 2011.

[43] Y. S. Salehi-Lisar and H. Bakhshayeshan-Agdam, "Drought stress in plants: causes, consequences, and tolerance," Drought Stress Tolerance in Plants, vol. 1, pp. 1-16, 2016. 